\title{
FAULT DIAGNOSIS OF SENSORS, ACTUATORS AND WIND TURBINE SYSTEM
}

\author{
Messaouda AZZOUZI ${ }^{1}$, Rokiatou DIARRA ${ }^{2}$, Dumitru POPESCU ${ }^{3}$ \\ ${ }^{1}$ Faculty of Sciences and Technology, University of Djelfa, BP. 3117 Djelfa 17.000, Algeria, \\ Dr.Azzouzi@yahoo.fr \\ ${ }^{2}$ University of Paris-Saclay, 91190 Saint-Aubin, France \\ ${ }^{3}$ Faculty of Automatic Control and Computers, University Politehnica of Bucharest, Romania
}

Abstract

The production capacity of installed wind power greatly increases in worldwide. Hence the interest is focused on the reliability and efficiency of wind turbines; then to reduce the production cost and increase the yield. The main objective of our research in this work is to diagnose wind system. We presented a state of the art of diagnosis approach applied on wind turbines and various occurred faults which should be detected and isolated in the wind turbine parts. After that, an overview on this proposed solution for wind turbines, which opted for a diagnostic strategy based on support vector machines (SVM). A Benchmark of a wind power of 4.5 MW with faults on sensors, actuators and the systems was presented. Defects of the Benchmark are in the pitch system, the drive system, the generator and the converter. We tested then the effectiveness of the used method by visualizing simulation results of diagnosis in two different scenarios.

Keywords: wind turbine, benchmark, faults, modeling, diagnosis, SVM, FDI.

\section{ABBREVIATIONS AND ACRONYMS}

\begin{tabular}{|c|c|c|}
\hline FDI & Fault Detection and Isolation & \\
\hline$S V M$ & Support Vector Machine & \\
\hline$\rho$ & Density of air & $\mathrm{Kg} / \mathrm{m}^{2}$ \\
\hline$C_{p}$ & power coefficient & \\
\hline$C_{q}(\lambda, \beta)$ & Coefficient of aerodynamic torque & \\
\hline$\lambda$ & $\lambda=w_{r} R / v_{w}$ Tip speed ratio & \\
\hline$R$ & Blade rays & $m$ \\
\hline$v_{w}$ & Wind speed & $\mathrm{m} / \mathrm{s}$ \\
\hline$\tau_{g, m}$ & Real torque of the generator & $\mathrm{Nm}$ \\
\hline$\beta$ & Pitch angle & deg \\
\hline$\beta_{k, m}, \beta_{k, d}$ & Measured and desired pitch angle & deg \\
\hline$w_{n}$ & Natural pulsation & $\mathrm{rad} / \mathrm{s}$ \\
\hline$\zeta$ & Damping coefficient & \\
\hline$J_{r}$ & Moment of inertia of the shaft at low speed & $K g \cdot m^{2}$ \\
\hline$\tau_{g, r}$ & Desired torque of the generator & $N m$ \\
\hline$\tau$ & Constant time $(\tau=0.02)$ & $s$ \\
\hline$w_{p, m}$ & $(p=g$ or $m)$ Measured speed of the generator and the rotor & $\mathrm{rad} / \mathrm{s}$ \\
\hline$J_{g}$ & Moment of inertia of the shaft at high speed & $K g \cdot m^{2}$ \\
\hline$K_{d t}$ & Torsional rigidity of training & $\mathrm{Nm} / \mathrm{rad}$ \\
\hline$B_{d t}$ & Coefficient of damped torsion & $\mathrm{Nm} /(\mathrm{rad} / \mathrm{s})$ \\
\hline$\theta_{\Delta}(t)$ & Angle of torsion & \\
\hline$\eta_{d t}$ & Performance of the drive train & \\
\hline$T_{e}, T_{D}$ & Sampling time and detection time & $s$ \\
\hline$N_{g}$ & Gear ratio & \\
\hline$B_{g}$ & Viscous friction of the shaft at high speed & $\mathrm{Nm} /(\mathrm{rad} / \mathrm{s})$ \\
\hline$\tau_{g}, \tau_{r}$ & Generator Rotor torques & $\mathrm{Nm}$ \\
\hline$w_{r}, w_{g}$ & Rotational speed of the generator and the rotor & $\mathrm{rad} / \mathrm{s}$ \\
\hline$P_{g}$ & Power produced by the generator & Watt $(W)$ \\
\hline$\hat{\beta}$ & Filtered value of $\beta$ & deg \\
\hline$\widehat{w}$ & Filtered value of $w$ & $\mathrm{rad} / \mathrm{s}$ \\
\hline
\end{tabular}




\section{INTRODUCTION AND RELATED WORK}

Renewable energies are modes of production of energy using forces or resources whose stocks are unlimited [1]. Mastering these new energies requires progress not only in technology but also in science in order to meet the increased energy demands worldwide [2]. The availability of advanced numerical methods along with improvement in the energy systems capabilities is opening new doors of opportunity for the development of technologies used in condition monitoring of these systems [3].

Various studies on wind turbine failure analysis have shown that the major occurred faults are bearing faults, gear faults, brake failure, generator problem, blade fault, wind tower faults, Blade issues and much more [4], [5]. Faults no matter where they are in wind turbine, cause abnormalities of various subsystems, which are reflected by the appearance of a significant harmonics [4], [6]. Diagnostic approach helps to obtain better operation of these systems to maximize the generation of electricity at a minimal cost while respecting safety conditions [7].

In recent years there has been some works on the problem of fault diagnosis in wind turbines including observer based on the detection of sensor faults in the wind turbine. In this method an observer based regime is proposed to detect sensor faults in wind turbines. A model of the chain transmission is used to design the observer in which the wind speed is an important input. The regime is applied to a set of sensor faults in terms of gain factor on the measurements [4], [8].

The paper is organized as follows:

- The first part contains the Benchmark modeling of the different subsystems of the wind turbine conversion system;

- The second part focuses on the FDI based on the support vector machine in which details of ten faults are given;

- The third part is dedicated to the results of simulation for two scenarios of detection and isolation of faults.

At last a conclusion was drawn.

\section{WIND TURBINE MODELLING}

The modeling of the wind turbine mainly represents its aerodynamic, mechanical and electrotechnical characteristics [2], [13]. The model studied is a turbine reference model including sensor, actuator and system faults.

This model describes a specific type of variable speed wind turbine, with a three-axis horizontal axis, a nominal power of $4.8 \mathrm{MW}$, and a complete converter. The reference model is described by Simulink diagram composed of the different subsystems of the wind turbine. This turbine model includes the following four blocks as presented in Fig. 1 [14] [15].

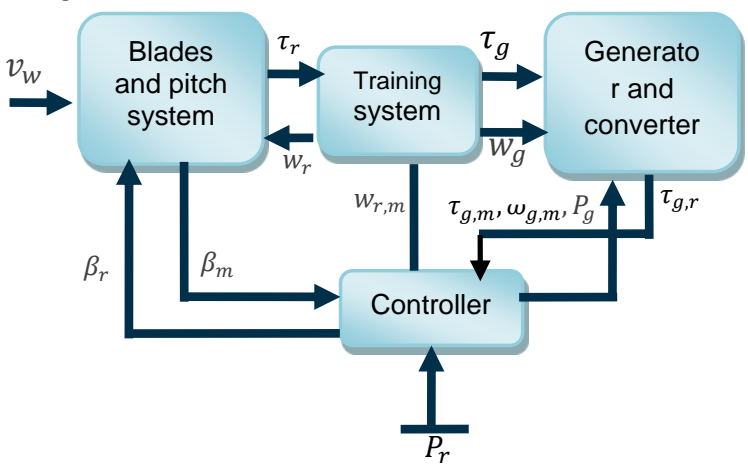

Fig. 1. Simulink scheme or the benchmark model of the wind turbine

\subsection{Blades and rigging system}

This block is a combination of the aerodynamic model and the blade timing model. The aerodynamic torque acting on the blades is given as follows:

$$
\tau_{r}(t)=\frac{\rho \pi R^{3} c_{q}(\lambda(t), \beta(t)), v_{w}(t)^{2}}{2}
$$

The hydraulic actuator can be modeled by a 2 nd order transfer function with constraints on each blade:

$$
\frac{\beta_{k, m}(s)}{\beta_{k, d}(s)}=\frac{w_{n}^{2}}{s^{2}+2 \zeta w_{n} s+w_{n}^{2}}
$$

\subsection{The converter and the generator}

The dynamics of the converter are modeled by a transfer function of the 1 st order :

$$
\frac{\tau_{g, m}(s)}{\tau_{g, r}(s)}=\frac{\alpha_{g c}}{s+\alpha_{g c}}
$$

The produced power by the generator is:

$$
P_{g}(t)=\eta_{g} w_{g}(t) \tau_{g}(t)
$$

\subsection{Training system}

The "drive train" drive system is modeled by a model with three state variables taking into account the inertia of the generator and the rotor. The dynamics of this system are given as follows [16]:

with :

$$
\left[\begin{array}{l}
\dot{w}_{r}(t) \\
w_{g}(t) \\
\theta_{\Delta}(t)
\end{array}\right]=A\left[\begin{array}{l}
w_{r}(t) \\
w_{g}(t) \\
\theta_{\Delta}(t)
\end{array}\right]+B\left[\begin{array}{l}
\tau_{r}(t) \\
\tau_{g}(t)
\end{array}\right]
$$

$$
\mathrm{A}=\left[\begin{array}{ccc}
\frac{-B_{d t}-B}{J_{r}} & \frac{B_{d t}}{N_{g} J_{r}} & -\frac{K_{d t}}{J_{r}} \\
\frac{\eta_{d t} B_{d t}}{N_{g} J_{g}} & \frac{-\frac{\eta_{d t} B_{d t}}{N^{2} g}-B_{g}}{J_{g}} & \frac{\eta_{d t} K_{d t}}{N_{g} J_{g}} \\
1 & -\frac{1}{N_{g}} & 0
\end{array}\right], B=\left[\begin{array}{cc}
\frac{1}{J_{r}} & 0 \\
0 & -\frac{1}{J_{g}} \\
0 & 0
\end{array}\right]
$$

\subsection{Controller}

The wind speed determines the area of operation of the controller and therefore the wind machine. The controller operates mainly in four areas: the start of the turbine, the optimization of the power, the constant production of the power, the high speed of the wind [5], [14]. 
In this model, there are different types of faults that can appear in the different subsystems of the reference model. Among these defects we have: sensor faults and actuator faults.

\section{FAULT DETECTION AND ISOLATION}

FDI's strategy will be based on Support Vector Machines (SVM) and consists in creating specific characteristics for each defect. Among these characteristics is the residue. SVM classification is used to evaluate generated residues in order to conclude on the system's operating status. SVM defect detection is developed in two parts. First, a set of data with and without defects is used to learn the detection patterns of each defect by using a given wind sequence as input. The obtained models are validated on a new fault scenario] [13], [14].

The key idea in learning a new model for SVM defect detection is the definition of the vector $\mathrm{x}$ to be used for classification. For each type of fault, a vector is defined.

Fixed value type (1a): The vector used for detection and isolation is:

$$
x=\left[\begin{array}{l}
\left|\hat{\beta}_{k, m 1}\left(t_{j}\right)-\hat{\beta}_{k, m 2}\left(t_{j-1}\right)\right| \\
\left|\hat{\beta}_{k, m 1}\left(t_{j}\right)-\hat{\beta}_{k, m 1}\left(t_{j-1}\right)\right| \\
\left|\hat{\beta}_{k, m 2}\left(t_{j}\right)-\hat{\beta}_{k, m 2}\left(t_{j-1}\right)\right|
\end{array}\right]
$$

Where $t_{j}$ and $t_{j-1}$ are respectively the instants of time $\mathrm{j}$ and $\mathrm{j}-1$ and $\hat{\beta}$ is the filtered value of $\beta$.

Gain type (1b): This fault is detected and isolated in two steps. First the defect is detected using the vector:

$$
x=\left[\begin{array}{c}
\left|\hat{\beta}_{k, m 1}\left(t_{j}\right)-\hat{\beta}_{k, m 2}\left(t_{j}\right)\right| \\
\left|\hat{\beta}_{k, m 1}\left(t_{j}\right)-\hat{\beta}_{k, m 1}\left(t_{j-1}\right)\right| \\
\left|\hat{\beta}_{k, m 2}\left(t_{j}\right)-\hat{\beta}_{k, m 2}\left(t_{j-1}\right)\right|
\end{array}\right]
$$

The second and third lines exclude type 1a defects. If the type $b$ fault is detected, it is isolated between the sensors 1 and 2 by the vector:

$$
x=\left[\begin{array}{l}
\left|\hat{\beta}_{k, d}\left(t_{j}\right)-\hat{\beta}_{k, m 1}\left(t_{j}\right)\right| \\
\left|\hat{\beta}_{k, d}\left(t_{j}\right)-\hat{\beta}_{k, m 2}\left(t_{j}\right)\right|
\end{array}\right]
$$

Where $\beta_{k, d}$ is the desired value of pitch angle $\beta_{k}$.

Fixed Value Types $2 a$ and $3 a$ : The following vector is used for detection and isolation:

$$
x=\left[\begin{array}{c}
\left|\widehat{w}_{p, m 1}\left(t_{j}\right)-\widehat{w}_{p, m 2}\left(t_{j}\right)\right| \\
\left|w_{p, m 1}\left(t_{j}\right)-w_{p, m 1}\left(t_{j-1}\right)\right| \\
\left|w_{p, m 2}\left(t_{j}\right)-w_{p, m 2}\left(t_{j-1}\right)\right|
\end{array}\right], p=g, r
$$

For defects 4 and 6 , the following vector is used: $x=$

$\left[\begin{array}{c}\left|w_{g, m 1}\left(t_{j}\right)-w_{g, m 2}\left(t_{j}\right)\right| \\ \left|\tau_{g, r}\left(t_{j}\right)-\tau_{g, m}\left(t_{j}\right)\right| \\ \lambda_{2}\left|w_{g}^{d}\left(t_{j}\right)-\left(w_{g, m 1}\left(t_{j}\right)+w_{g, m 2}\left(t_{j}\right)\right) / 2\right|\end{array}\right]$

Where $w_{g}^{d}=\frac{P_{r}}{\tau_{g, r}} \quad$ is the speed of the desired generator. The factor $\lambda_{2}=10^{-10} * v_{w}^{6}$ is used to account for wind speed and for normalization.

For defects $5 \mathrm{a}$ and $5 \mathrm{~b}$, the following vector is used for detection and isolation:

$$
x=\left|\begin{array}{c}
\left|w_{g, m 1}\left(t_{j}\right)-w_{g, m 2}\left(t_{j}\right)\right| \\
\left|\beta_{k, m 1}\left(t_{j}\right)-\beta_{k, m 2}\left(t_{j}\right)\right| \\
\left|\beta_{k, m 1}\left(t_{j}\right)-\beta_{k, m 1}\left(t_{j-1}\right)\right| \\
\left|\beta_{k, m 2}\left(t_{j}\right)-\beta_{k, m 2}\left(t_{j-1}\right)\right|
\end{array}\right|
$$

Table. Parameters and requirements of faults handled by the FDI

\begin{tabular}{|c|c|l|c|}
\hline Nr of fault & Type of fault & \multicolumn{1}{|c|}{ Parameters } & Time period \\
\hline $\mathbf{1}$ & $1 \mathrm{a}$ & $\beta_{1, m 1}=5^{\circ}$ & $2000 \mathrm{~s}-2100 \mathrm{~s}$ \\
\hline $\mathbf{2}$ & $1 \mathrm{~b}$ & $\beta_{2, m 2}=1.2 \beta_{2, m 2}$ & $2300 \mathrm{~s}-2400 \mathrm{~s}$ \\
\hline $\mathbf{3}$ & $1 \mathrm{a}$ & $\beta_{3, m 1}=10^{\circ}$ & $2600 \mathrm{~s}-2700 \mathrm{~s}$ \\
\hline $\mathbf{4}$ & $2 \mathrm{a}$ & $w_{r, m 1}=1.4 \mathrm{rad} / \mathrm{s}$ & $1500 \mathrm{~s}-1600 \mathrm{~s}$ \\
\hline $\mathbf{5}$ & $2 \mathrm{~b}$ and $3 \mathrm{~b}$ & $w_{r, m 2}=1.1 w_{r, m 2}$ and $w_{g, m 1}=0.9 w_{g, m 1}$ & $1000 \mathrm{~s}-1100 \mathrm{~s}$ \\
\hline $\mathbf{6}$ & $5 \mathrm{a}$ & Sudden change (actuator of pitch 2) & $2900 \mathrm{~s}-3000 \mathrm{~s}$ \\
\hline $\mathbf{7}$ & $5 \mathrm{~b}$ & Slow change (actuator of pitch 3) & $\begin{array}{c}\text { Faults start at } 3500 \mathrm{~s} \text { and } \\
\text { finish at } 3600 \mathrm{~s}\end{array}$ \\
\hline $\mathbf{8}$ & $4 \mathrm{a}$ & $\tau_{g}=\Delta \tau_{g}+2000 \mathrm{Nm}$ & $3800 \mathrm{~s}-3900 \mathrm{~s}$ \\
\hline
\end{tabular}




\section{SIMULATION RESULTS}

The benchmark model of wind energy we use is the model developed by kk-electronic. Afterwards, we will apply our diagnostic system to this model. The nominal operating case corresponds to the reference parameters of the benchmark given in appendix A [15].

Fig. 1 and Fig. 2 show respectively the evolution as a function of time of the wind speed (the input) and the electric power generated (the output). It is clear that there is a great relationship between the wind speed and the generated electric power. The power is maximum when the wind speed reaches a certain value [17].

$$
v_{w}[\mathrm{~m} / \mathrm{s}]=f(t[s])
$$

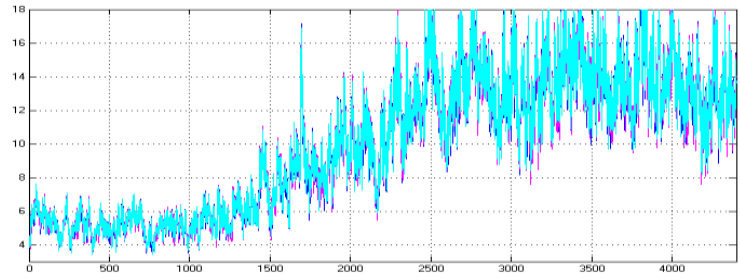

Fig. 1. Wind speed

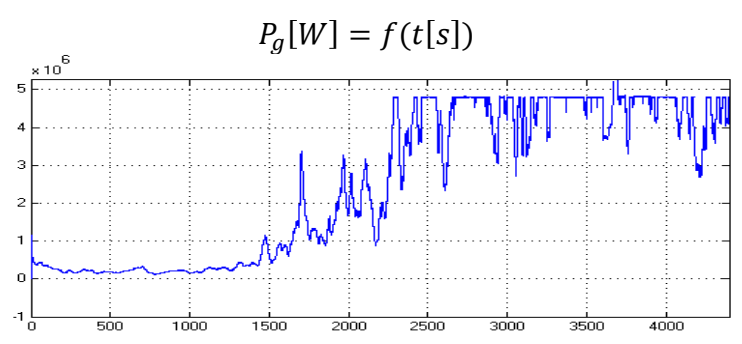

Fig. 2. Generated electric power in nominal operating

Two fault scenarios were used. in which we vary the reference parameters and the requirements in terms of detection and isolation time as shown in the appendix B.

\subsection{Scenario 1}

Five faults were detected and isolated simultaneously in this scenario. Fig. 3 shows the electrical power generated in this scenario. We find that the production of energy is influenced by the command. We observe a fault between the instants $2000 \mathrm{~s}$ and $2200 \mathrm{~s}$. This is due to a fault in the drive system.

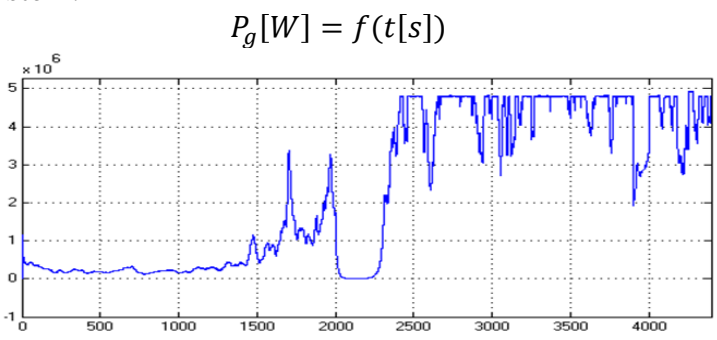

Fig. 3. Electrical power generated in scenario 1
There is no fault coming from the sensor $\beta_{2, m 1}$ so the measurement error on pitch 2 comes from the sensor $\beta_{2, m 2}$. Fig. 4 shows the decision result of fault 2 in the sensor $\beta_{2, m 2}$ as well as the measurement of the sensor $\beta_{2, m 2}$. We notice that the fault appears between the instants 2500 s and 2600s. It is detected at the moment $2500.03 \mathrm{~s}$ and well isolated [16], [17].
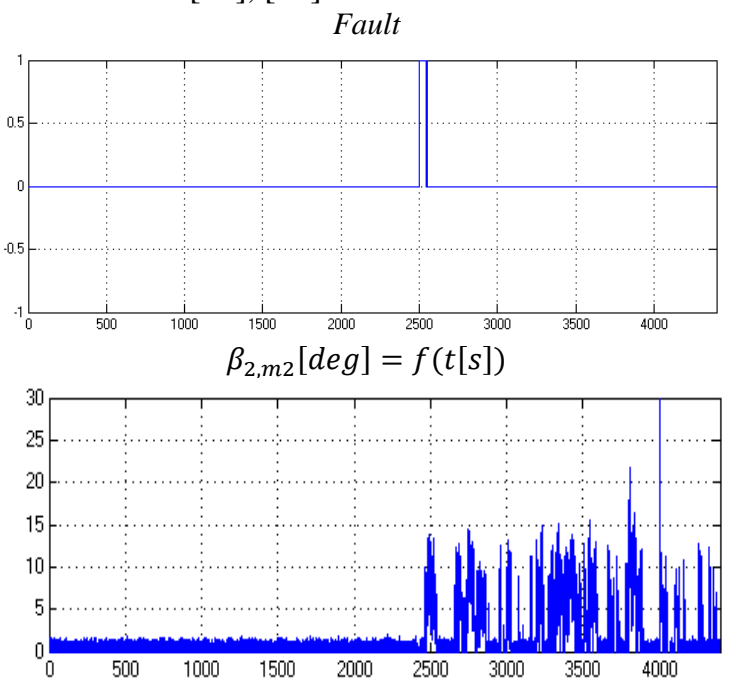

Fig. 4. Detection et isolation of fault 2 on the sensor $\beta_{2, m 2}$

Fig. 5 shows the sensor measurement $\omega_{r, m 1}$ and the result of the fault decision. We note the existence of a fault between the times $1200 \mathrm{~s}$ and $1300 \mathrm{~s}$. It is a fixed value defect. This is the fault 4. It is instantly detected at the instant $1200.02 \mathrm{~s}$. Note that the detection signals on other faults display a value of zero [13].
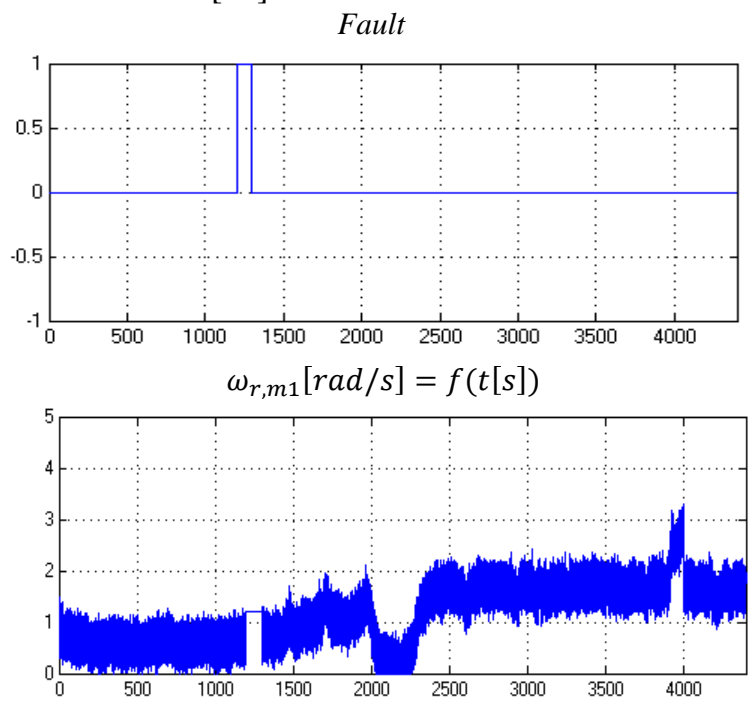

Fig. 5. Detection et isolation of fault 4 on the of the rotor speed sensor $\omega_{r, m 1}$

Fig. 6. shows the sensor measurements $\omega_{r, m 2}$ and the result of the fault decision. We notice the existence of a defect, of type gain. It is the fault 5 . It appears between the instants 1700s and 1800s. The measurement of $\omega_{g, m 1}$ which is also influenced 
by disturbances and other types of faults which makes the isolation task more complicated. However the defect was detected and isolated between the instants $1700.03 \mathrm{~s}$ and $1800.06 \mathrm{~s}$ [13].
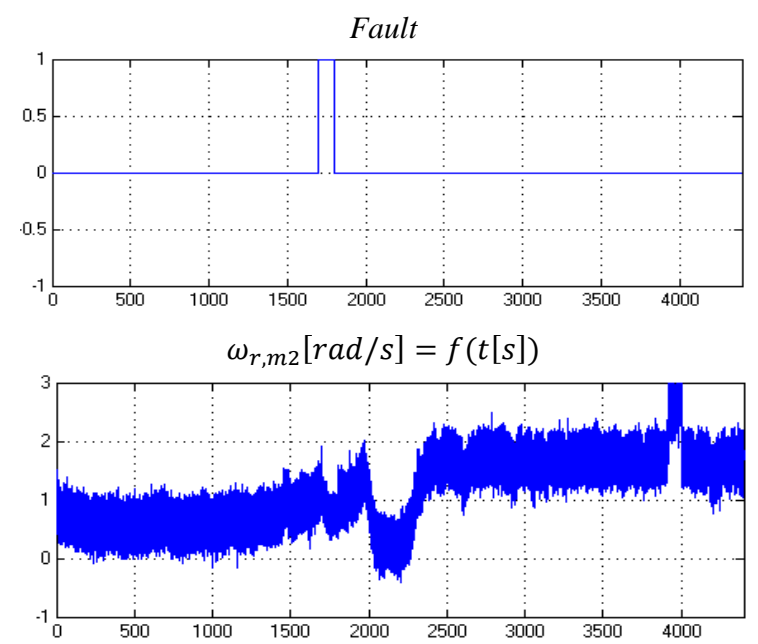

Fig. 6. Detection and isolation of the fault 5

(2b) on the rotor speed sensor $\omega_{r, m 2}$

Fig. 7 measures the rotational speed sensor of the generator $\omega_{g, m 1}$ as well as the fault decision result. We note the existence of a gain-type defect that appears between the times $1700 \mathrm{~s}$ and $1800 \mathrm{~s}$. This is the fault 5 (3b). It is detected and isolated during the same time interval [17].
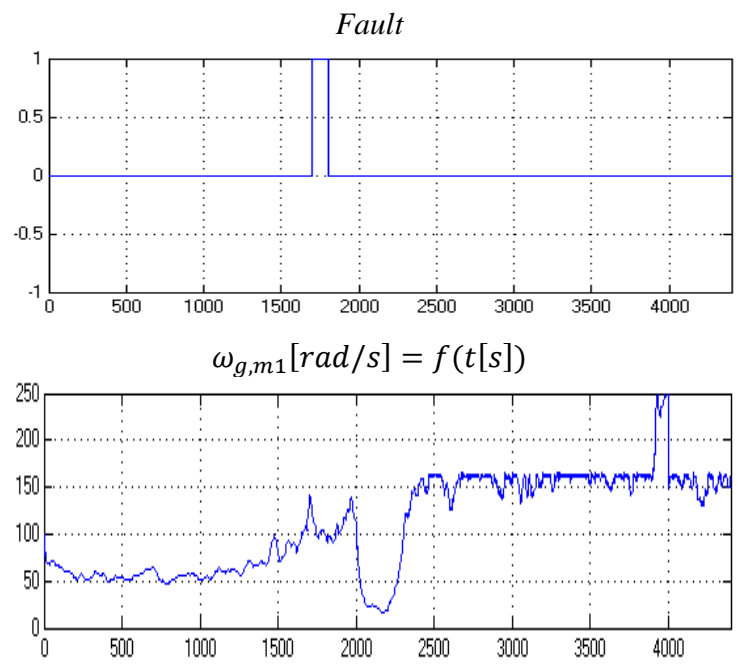

Fig. 7. Detection and isolation of fault 5 (3b) on the sensor $\omega_{\mathrm{g}, \mathrm{m} 1}$

Fig. 8 shows the measurements of the torque $\tau_{g}$ and the decision of fault. We find the existence of a defect. This is the fault 8 . The detection is performed instantly at $4200.02 \mathrm{~s}$ instant.

\subsection{Scenario 2}

In this scenario, three defects were detected simultaneously. Fig. 9 shows the electrical power generated in this scenario. We find that the generator took a long time to actually start producing [16].
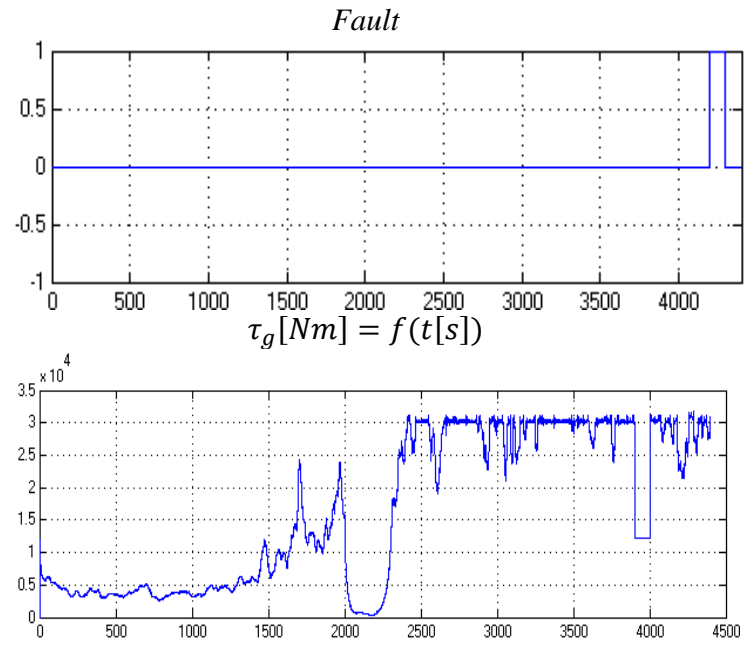

Fig. 8. Detection and isolation of fault 8 on the converter actuator

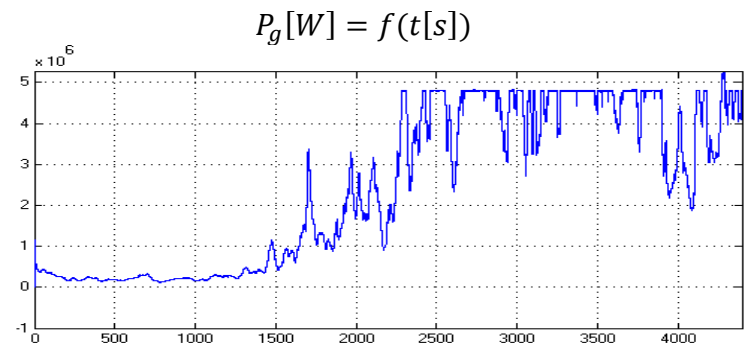

Fig. 9. Electrical power generated in scenario 2

Fig. 10 shows the sensor measurements $\beta_{1, m 1}$ and the fault result. We notice the presence of a fixed value defect. This is the fault 1 , it is detected and isolated between the instants $245 \mathrm{~s}$ and $345 \mathrm{~s}$ [17].
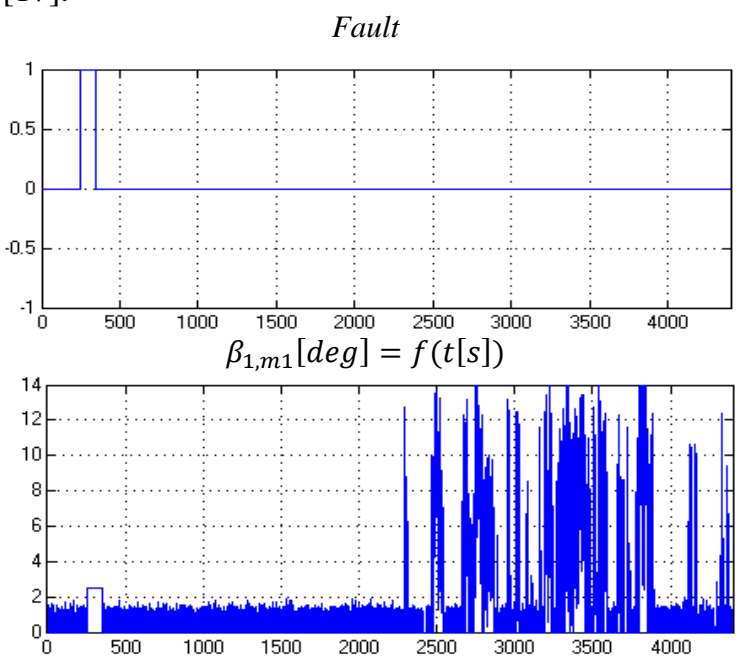

Fig. 10. Detection and isolation of fault 1 on the sensor $\beta_{1, m 1}$ in scenario 2

Fig. 11 shows the rotational speed sensor $\omega_{m, 1}$ measurements of the rotor. We notice the existence of a fixed value defect. It is fault 4 , which is detected and isolated between times $800 \mathrm{~s}$ and $900 \mathrm{~s}$ [17]. 


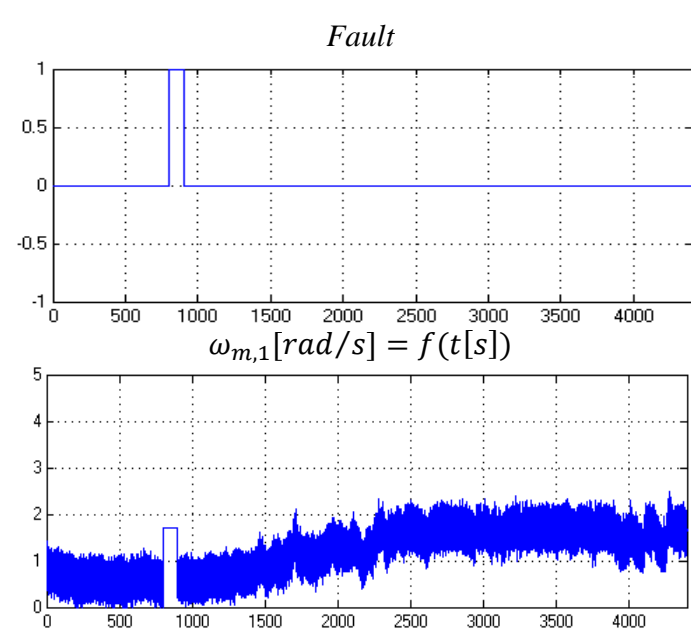

Fig. 11. Detection and isolation of fault 4 on the rotational speed of the rotor in scenario 2

Fig. 12 shows the sensor measurements $\omega_{r, m 2}$ of the rotational speed of the rotor and the result of the fault decision. We note that a gain-type defect appears between the instant $2200 \mathrm{~s}$ and $2300 \mathrm{~s}$. This is the fault $5(2 b)$, it is detected and isolated during the same time interval [13], [17].

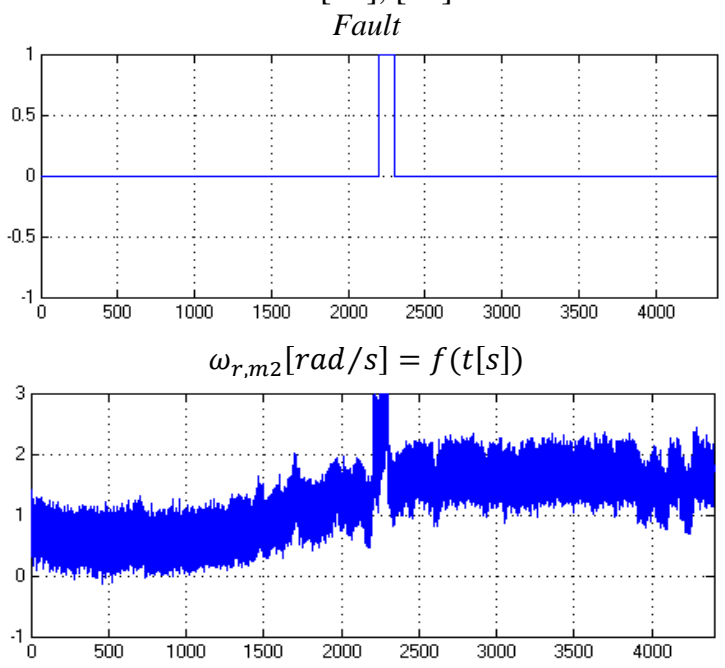

Fig. 12. Detection and isolation of fault $5(2 b)$ on the rotational speed of the rotor in scenario 2

\section{CONCLUSION}

The research work deals with the problem of fault diagnosis in wind systems. The previously defined goal of this work was to model a fault diagnosis system for a wind energy system and propose sophisticated technique which provides much diagnostic information. A wind Benchmark with defined parameters was simulated and so affected by sensor, actuator and system faults which were used to perform the tests. We used the support vector machine method for fault detection and isolation. This allowed us to easily manipulate noise, disturbances and outliers.

The performance of the developed method was evaluated using two fault scenarios with different parameters considered in the wind energy
Benchmark. Satisfactory results have been obtained when all defects could be detected and then isolated as soon as possible and in different operating points at which the faults are occurred. As a perspective for future research work, we suggest the study of wind energy Benchmarks with simultaneous faults then we will design fault tolerant control. This will test the robustness of the proposed solution.

\section{REFERENCES}

1. Saravanakumar R, Manimozhi M, Kothari DP. Simulation of sensor fault diagnosis for wind turbine generators DFIG and PMSM using Kalman filter, Energy Procedia. 2014; 54:494-505.

2. Hilbert M, Küch C, Nienhaus K. Model based fault detection of wind turbine drive trains. Chemical Engineering Transactions. 2013; 33: $37-942$ https://doi.org/10.3303/CET1333157

3. Rashid MH. Energy Systems in Electrical Engineering, Series Ed. Springer Book.

4. Odgaard PF, Stroustrup J. A benchmark evaluation of fault tolerant wind turbine control concepts. IEEE Transactions on Control Systems Technology, 2014: 1063-6536.

5. Joshuva A, Sugumaran V. Fault diagnostic methods for wind turbine: A review. ARPN Journal of Engineering and Applied Sciences. 2016; 11(7):46544668.

6. Kusiak $\mathrm{A}, \mathrm{Li} \mathrm{W}$. The prediction and diagnosis of wind turbine fault. Renewable Energy. 2011; 36(1):16-23.

7. Chakkor S, Baghouri M, Hajraoui A. Real time remote monitoring and fault detection in wind turbine. International Scholarly and Scientific Research \& Innovation, 2014; 8(9).

8. Elijorde F, Kim S, Lee J. A wind turbine fault detection approach based on cluster analysis and frequent pattern mining. KSII Transactions on Internet and Information Systems (TIIS). 2014:664677. http://dx.doi.org/10.3837/tiis.2014.02.0019

9. Odgaard PF, Stroustrup J, Kinnaert M. Fault tolerant control of wind turbines: a Benchmark model. IEEE Transactions on Control Systems Technology; 2014; 21(4)

10. Kusiak A, Wenyan, L. The prediction and diagnosis of wind turbine faults. Renewable Energy. 2011; 36(1):16-23.

11. Leahy K, Lily Hu R, Konstantakopoulos LV, Spanos CJ, Agogino AM. Diagnosing wind turbine faults using machine learning techniques applied to operational data. IEEE International Conference on Prognostics and Health Management (ICPHM). 2016.

12. Nadhir A, Naba A, Hiyama T. Intelligent gradient detection on MPPT control for variable speed wind energy conversion system. ACEEE Int. J. on Electrical and Power Engineering. 2011; 2(2).

13. Laouti N. Fault diagnosis by vectors machines supports: application to different nonlinear multivariable systems. French, PhD thesis, University of Claude Bernard Lyon. 2012.

14. Blesa J, Rotondo D, Puig V, Nejjari F. FDI and FTC of wind turbines using the Interval Observer approach and Virtual Actuators/Sensor. Control Engineering Practice. 2013; 24:138-155.

15. Tabatabaeipour SM, Odgaard PF, Thomas PFB. Fault detection of a Benchmark wind turbine using interval 
analysis, The 2012 American Control Conference (ACC. 2012:4387-4392.

16. Tang L, Decastro JA, Zhang X. Diagnosis of engine sensor, actuator and component faults using a bank of adaptive nonlinear estimators, IEEE Aerospace Conference Proceedings. 2011. http://dx.doi.org/10.1109/AERO.2011.5747565

17. Denton T. Advanced automotive fault diagnosis. Routledge, 2012.

18. Diarra R. Fault diagnosis of wind turbine conversion system, French, Master project, Industrial IT, University Ziane Achour of Djelfa, 2015.

\section{Received 2018-05-26}

Accepted 2018-09-03

Available online 2018-09-04

Appendix A: Parameters of the wind turbine system Benchmark model

\begin{tabular}{|c|c|c|c|}
\hline 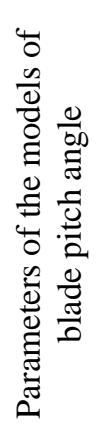 & 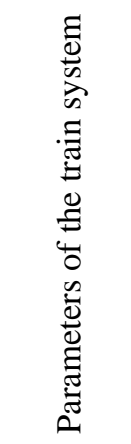 & 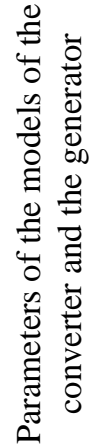 & 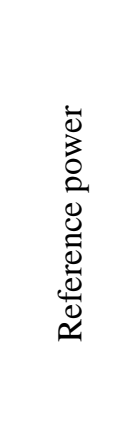 \\
\hline $\mathrm{R}$ & $B_{d t}$ & \multirow{4}{*}{$\alpha_{g c}$} & \multirow{17}{*}{$4.5^{*} 10^{6}$} \\
\hline 57.5 & 775.49 & & \\
\hline$\rho$ & $B_{r}$ & & \\
\hline 1.225 & 7.11 & & \\
\hline$\zeta$ & $B_{g}$ & \multirow{5}{*}{50} & \\
\hline 0.6 & 45.6 & & \\
\hline$w_{n}$ & $N_{g}$ & & \\
\hline 11.11 & 95 & & \\
\hline$\zeta_{2}$ & $K_{d t}$ & & \\
\hline 0.45 & $2.7 * 10^{9}$ & \multirow{5}{*}{$\eta_{g c}$} & \\
\hline$w_{n 2}$ & $\eta_{d t}$ & & \\
\hline 5.73 & 0.97 & & \\
\hline$\zeta_{3}$ & $\eta_{d t 2}$ & & \\
\hline 0.9 & 0.92 & & \\
\hline \multirow{2}{*}{$w_{n 3}$} & $J_{g}$ & \multirow{3}{*}{0.98} & \\
\hline & 390 & & \\
\hline 3.42 & $\frac{J_{r}}{55^{*} 10^{6}}$ & & \\
\hline
\end{tabular}

Appendix B : Parameters of scenario 1 and scenario 2

\begin{tabular}{|c|c|c|c|c|}
\hline \multicolumn{5}{|c|}{ Scenario 1 } \\
\hline$\beta_{1, m 1}$ & $\beta_{2, m 2}$ & $\beta_{3, m 1}$ & $\omega_{r, m 1}$ & $\omega_{r, m 2}$ \\
\hline 4 & 41.8 & 12 & 1.2 & $0.7 \omega_{r, m 2}$ \\
\hline$\tau_{g c}$ & \multicolumn{2}{|c|}{$\omega_{g, m 2}$} & $\eta_{d t 2}$ & $\omega_{g, m 1}$ \\
\hline 700 & $1.7 \omega_{g, m 2}$ & 0.3 & 100 \\
\hline \multicolumn{5}{|c|}{ Scenario 2} \\
\hline$\beta_{1, m 1}$ & $\beta_{2, m 2}$ & $\beta_{3, m 1}$ & $\omega_{r, m 1}$ & $\omega_{r, m 2}$ \\
\hline 2.5 & $4 \beta_{2, m 2}$ & 13 & 1.7 & $1.7 \omega_{r, m 2}$ \\
\hline$\tau_{g c}$ & \multicolumn{2}{|c|}{$\omega_{g, m 2}$} & $\eta_{d t 2}$ & $\omega_{g, m 1}$ \\
\hline-500 & $0.7 \omega_{g, m 2}$ & 0.6 & 150 \\
\hline
\end{tabular}

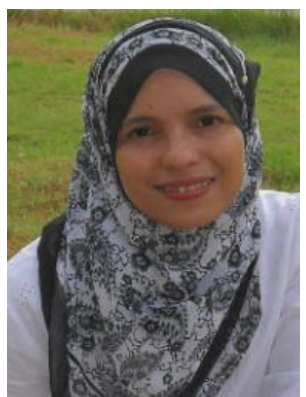

Messaouda AZZOUZI was born in Djelfa (Algeria), she had got her Engineering diploma in electronics from Ziane Achour University of Djelfa (Algeria) in 2002. She had finished her $\mathrm{PhD}$ thesis in automatic control form Politehnica University of Bucharest (Romania) in 2008.

Actually she is an associate professor at the Ziane Achour University of Djelfa (Algeria) and she is the head of the LMD Electronics specialty.

Dr. Azzouzi has publications in many journals and she participated in many international conferences. She served as reviewer and editor of known journals and she was been joined as organizing/scientific/ international program committees member of many international conferences.

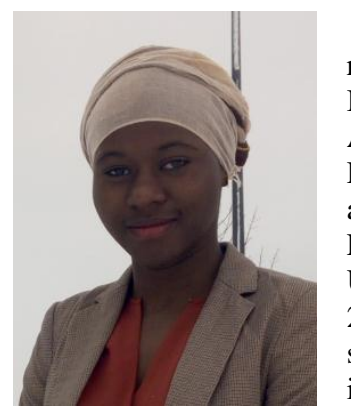

Rokiatou DIARRA received the MASc degree in Industrial Computing and Automatic from University of Djelfa in 2015. She received another MASc degree in Embedded System from University of Paris Sud in 2016. She is currently in her second year of her PhD degree in the laboratory of Systems and Applications of Information and Energy Technologies at the University of Paris Saclay. Her research interest are in the areas of heterogeneous computing systems, embedded systems, parallel programming models, general purpose GPU computing and automatic.

Dumitru POPESCU was born in Bucharest (Romania) in 1944. $\mathrm{He}$ is professor at faculty of automatic control and computers, University Politehnica of Bucharest (UPB) since 1990. He got his engineering diploma in electronics in 1966 from the Polytechnic Institute of Bucharest as well as his Ph.D. degree in Automatic Control and Systems Engineering in 1978. 


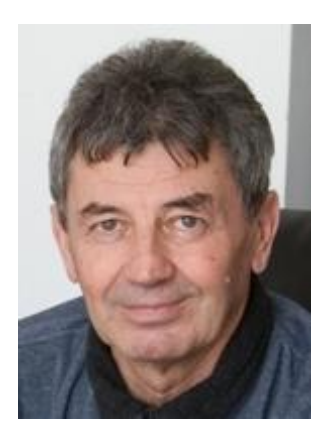

Prof. Popescu has teaching experience in UPB and other prestigious foreign universities. $\mathrm{He}$ is the director of ACPC Research Centre. $\mathrm{He}$ is $\mathrm{PhD}$ advisor and co-advisor with European universities and he participated in many national and international conferences/public events as chair, co-chair, session chair. $\mathrm{He}$ is member of various professional associations: IFAC/ TC-CPC, IFAC/TCBIOC, EUCA, SRAIT. More than that, he has collaborations in international scientific research projects and he has been awarded several times. 